\title{
Microencapsulation of $L$. acidophilus NRRL B-4495 in whey Protein-Pullulan Microparticles: Influence of Pullulan Concentration and Outlet Temperature
}

\author{
Burcu Çabuk ${ }^{*}$ and Sebnem Tellioglu Harsa*
}

\section{Department of Food Engineering, Izmir Institute of Technology, Gülbahçe Campus, Urla-Izmir, Turkey}

\begin{abstract}
Spray drying technique is one of the oldest methods adapted to many industrial areas to protect bioactive components. In this study, $\mathrm{pH}$ and heat tolerance of encapsulated probiotic Lactobacillus acidophilus NRRL B-4495 cells were investigated. Additionally, influence of process conditions including outlet temperature and pullulan concentration on spray drying process was observed. Scanning electron microscopy images showed that incorporation of pullulan higher than $2.0 \%$ in wall matrix created huge amount of fibrous particles. Spherical microcapsules having smooth surface were formed with $2.0 \%$ pullulan (WPI-pullulan ${ }_{4.5: 1}$ ) formulation leading to an improvement of barrier properties of microcapsules. Moreover, incorporation of pullulan improved the survival rate to $94.21 \%$ after spray drying. Results suggested that decreasing outlet temperature exhibited much higher cell survivals up to $92.68 \%$. However, between outlet temperatures, significant differences $(p \leq 0.05)$ in moisture content and recovery of final product indicated that more effective encapsulation of $L$. acidophilus NRRL B-4495 cells was achieved at $50{ }^{\circ} \mathrm{C}$. During spray drying, due to dehydration and high heat, cytoplasmic membrane of bacterial cells undergo damage and therefore, microencapsulation in WPI-pullulan blend by spray drying provided the highest survival against heat stress at $45 \stackrel{\circ}{ }{ }^{\circ}$. Moreover results showed that encapsulated cells survived at minimum desired level (7 log CFU/g) at pH 2.0 in contrast to free cells.
\end{abstract}

Keywords: Encapsulation, spray drying, microcapsule, pullulan, L. acidophilus.

\section{INTRODUCTION}

Due to long storage periods or difficulties in handling in large volumes, bioactive compounds including probiotics are generally preferred to be used in dehydrated forms [1-3]. Spray drying is one of the oldest methods adapted to many industrial areas to make powders and capturing bioactive components. However, viability losses of probiotic bacteria after spray drying have extensively been stated in literature and these studies indicated that functionality of encapsulated bioactive materials are mainly based on outlet temperatures, noozle dispersion size, viscosity, solid concentration of stock polymer-bioactive solution. Moreover, recent studies have shown that inclusion of carbohydrates improves the survival of spray dried probiotics [4-6]. But increase in survival rate depended on the type of the carbohydrate used in the formulation $[6,7]$. Therefore the present study aimed to investigate the influence of production variables including pullulan concentration and outlet temperature on survival of encapsulated cells in simulated gastic conditions including gastric juce, intestinaş juice and. Moreover, effects on physicochemical properties of spray dried $L$. acidophilus NRRL B-4495 cells were studies as well.

*Address correspondence to these authors at the Department of Food Engineering, Izmir Institute of Technology,Gülbahçe Campus, Urla-Izmir, Turkey; Tel: +90 232 7506291; Fax: +90 232 7506196;

E-mail: sebnemharsa@iyte.edu.tr, buc712@mail.usask.ca

\section{MATERIALS AND METHODS}

\section{Preparation of Microcapsules}

WPI-pullulan polymer blend containing $L$. acidophilus NRRL B-4495 with the initial cell load of 9.7 log $\mathrm{CFU} / \mathrm{g}$ to be microencapsulated by spray drying was carried out using laboratory spray dryer $(\mathrm{BÜCHI}$ Mini Spray dryer B-290, BÜCHI Labortechnik AG, UK). In this study, all conditions were fixed (aspiration rate of $70 \%$, flow rate of the peristaltic pump $15 \mathrm{ml} / \mathrm{min}$ ) and the outlet air temperatures were $35,45,50$ and $55^{\circ} \mathrm{C}$ and. The powders were collected in a single-cyclone separator. The microencapsulation of bacteria under different conditions of encapsulation was performed in triplicate. The resultant spray-dried bacteria were stored separately in $5 \mathrm{~g}$ quantities in sealed sterile glass bottles at $4^{\circ} \mathrm{C}$.

\section{Bacterial Enumeration}

$10 \mathrm{~g}$ of spray dried microcapsules were diluted with peptone water. This peptone water containing microcapsules was stirred at $890 \mathrm{rpm}$ for $5 \mathrm{~min}$ for complete dissolution. Samples of $1 \mathrm{ml}$ of the peptone water were diluted to an appropriate dilution and plated by the pour plate technique using MRS agar. Colonies were counted after $72 \mathrm{~h}$ of incubation at $37^{\circ} \mathrm{C}$.

Tolerance to Simulated Gastrointestinal Conditions

\section{Tolerance to Simulated Gastric Juice}

$1.0 \mathrm{ml}$ of free or $0.1 \mathrm{~g}$ of microencapsulated bacteria were transferred into $9.0 \mathrm{~g}$ of simulated gastric juice 
and incubated at $37{ }^{\circ} \mathrm{C}$ under orbital shaking at 160 rpm for $3 \mathrm{~h}$. After the incubation, samples were removed and viable bacteria were enumerated.

\section{Tolerance to Bile Salt Solution}

MRS media was supplemented with $0.6 \%$ ox-bile, $1.0 \mathrm{ml}$ of free or $0.1 \mathrm{~g}$ of microencapsulated $L$. acidophilus NRRL-B 4495 were inoculated into $9.0 \mathrm{~g}$ of prepared MRS medium and incubated at $37^{\circ} \mathrm{C}$ under orbital shaking at $160 \mathrm{rpm}$ for $24 \mathrm{~h}$. After the incubation, samples were removed and viable bacteria were enumerated.

\section{Release into Simulated Intestinal Juice}

$0.1 \mathrm{~g}$ of microencapsulated bacteria were transferred into the $9.0 \mathrm{~g}$ of simulated intestinal juice and incubated at $37^{\circ} \mathrm{C}$ under orbital shaking at $160 \mathrm{rpm}$ for $24 \mathrm{~h}$. After the incubation, samples were taken from supernatant and viable bacteria released in SIJ were enumerated

\section{Physicochemical Characterization}

Water activity of the microcapsules was determined using a Hygrolab C1 water activity meter (Hygrolab C1, Rotronic, Bassersdorf, Switzerland) [8]. The moisture content of the microcapsules was determined gravimetrically by oven-drying at $105^{\circ} \mathrm{C}$ for $24 \mathrm{~h}$ to reach weight equilibrium [9]. The mean $M C$ was estimated by the following equation:

$$
\mathrm{MC}(\%)=\left[\left(\mathrm{W}_{\text {wet }}-\mathrm{W}_{\text {dry }}\right) / \mathrm{W}_{\text {wet }}\right]^{*} 100
$$

where, $W_{\text {wet }}$ is the weight of the wet microcapsules and $W_{\text {dry }}$ is the weight of fully dry microcapsules.

Konica Minolta colorimeter (Model CR 410, Tokyo, Japan) was used for color measurements. The dissolution time of microencapsulated bacteria were characterized by suspending $5 \mathrm{~g}$ of spray dried microcapsules in $50 \mathrm{ml}$ of denionized water/simulated gastric juice/simulated intestinal juice and followed by stirring at $880 \mathrm{rpm}$. The time as seconds required for spray dried microcapsules was given in terms of dissolution time.

\section{RESULTS AND DISCUSSION}

\section{Influence of Pullulan Concentration}

WPI-pullulan polymer blend with selected concentrations of pullulan (Table 1) mostly created huge content of fibers and proper microcapsule formation was not achieved except WPI-pullulan $4.5: 1$ formulation (Figure 1). Moreover, these fibers showed very high resistance against dissolution in simulated intestinal juice. Thus WPI-pullulan ${ }_{4.5: 1}$ formulation was used for next experiments. Formation of fibers has also been reported by Koç [10] while studying on microencapsulation of whole egg by spray drying. Moreover, increasing pullulan content decreased the recovery of final product due to high adhesion of powder on the walls of drying cyclone unit. This can be explained by the high hydrophilic nature of pullulan as increasing pullulan content caused higher moisture level in the final spray dried microcapsules. As shown in Table 2, comparisons were made between non pullulan containing control and WPI-pullulan $4.5: 1$ and presence of pullulan provided enhanced survival of probiotic bacteria during spray drying. Survival rate of probiotic bacteria increased approximately $8 \%$ by encapsulation in WPI-pullulan polymer blend by spray drying technique. In addition, pullulan incorporation represented survival rates over $80 \%$ in simulated gastric juice and bile salt solution.

Table 1: Pullulan Concentrations Used in Spray Drying Studies

\begin{tabular}{|c|c|}
\hline Pullulan concentration (\%) & WPI-pullulan $_{\mathbf{y}}$ \\
\hline \hline 0 (Control) & WPI-pullulan $_{1: 0}$ \\
\hline 2.0 & WPI-pullulan $_{4.5: 1}$ \\
\hline 4.5 & WPI-pullulan \\
$2: 1$ \\
\hline 9.0 & WPI-pullulan \\
$1: 1$ \\
\hline 18 & WPI-pullulan \\
$1: 2$ \\
\hline
\end{tabular}

\section{Influence of Outlet Temperature}

Increase in the air outlet temperature was linked to an enhancement in recovery of spray dried microcapsules and linked to a decrease in survival rate during storage (Table 3). All samples represented decreased viable cell counts to $9.07,8.82,8.71$ and $7.58 \mathrm{log} \mathrm{CFU} / \mathrm{g}$ from an initial cell load of $9.86 \mathrm{log}$ $\mathrm{CFU} / \mathrm{g}$. At temperatures below $50^{\circ} \mathrm{C}$, since the evaporation rate was slower, spray dried microcapsules with higher moisture content were obtained causing high stickiness of the spray dried powders on the walls of drying chamber and reducing the recovery of the final product. However, high recovery values were obtained at/above $50^{\circ} \mathrm{C}$. It seems that at an outlet temperature of $50^{\circ} \mathrm{C} \mathrm{L}$. acidophilus NRRL B-4495 cells were encapsulated satisfactorily to produce spray dried microcapsules. Decreasing 


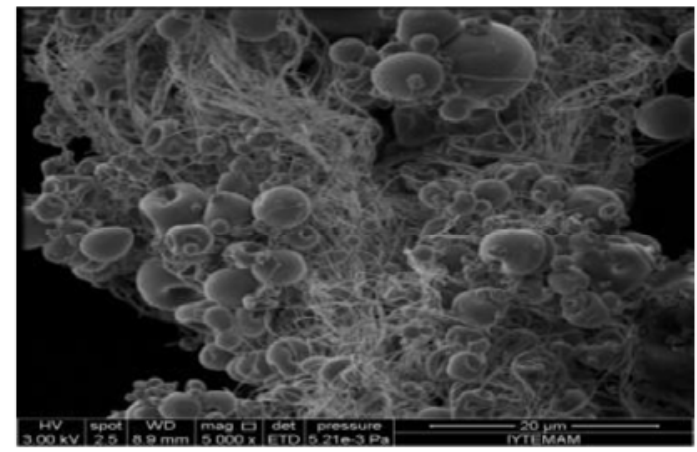

A

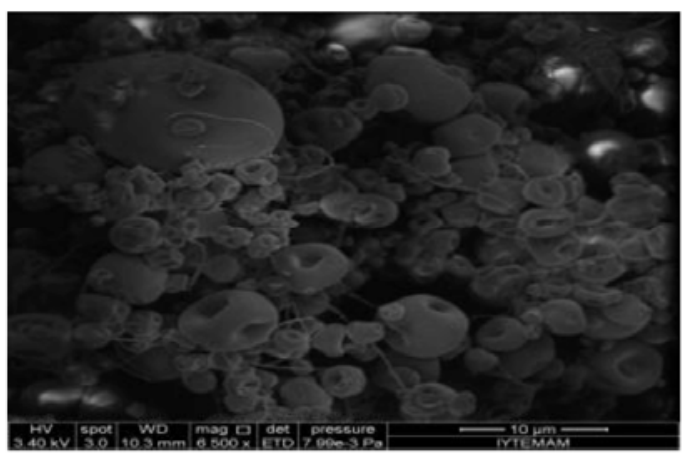

C

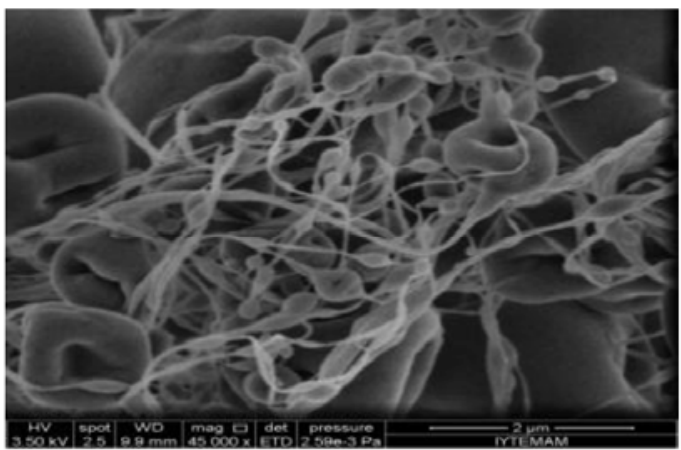

B

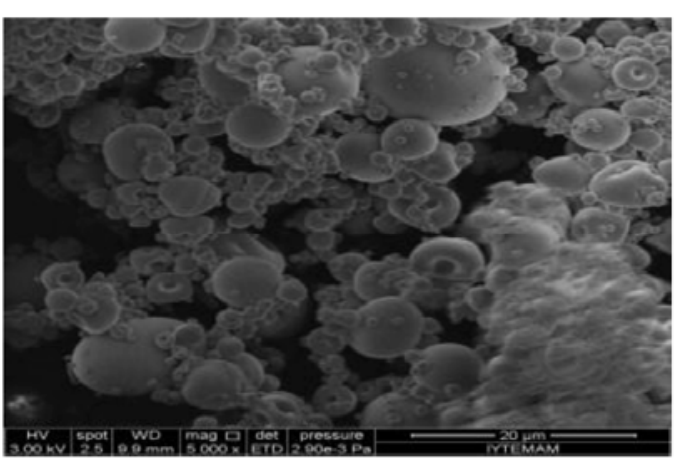

D

Figure 1: Scanning electron microscopic images of spray dried microcapsules A) WPI-pullulan ${ }_{1: 2}$ B) WPI-pullulan 1:1 $_{1}$ C) WPIpullulan $2: 1$ D) WPI-pullulan $4.5: 1$.

Table 2: Gastrointestinal Survival of Spray Dried WPI-Pullulan Microcapsules Loaded with L. acidophilus NRRL B-4495

\begin{tabular}{|c|c|c|}
\hline Microcapsule properties & \multicolumn{2}{|c|}{ Microcapsule formulation $^{2}$ WPI-pullulan $_{4.5: 1}$} \\
\cline { 2 - 3 } & WPI-pullulan $_{1: 0}$ & $94.21^{\mathrm{B}}$ \\
\hline \hline Survival rate (\%) & $86.43^{\mathrm{A}}$ & $8.72^{\mathrm{B}}$ \\
\hline Microbial load (Log CFU) & $7.99^{\mathrm{A}}$ & $81.03^{\mathrm{B}}$ \\
\hline Simulated gastric juice survival (\%) & $71.11^{\mathrm{A}}$ & $86.54^{\mathrm{B}}$ \\
\hline Bile survival (\%) & $81.36^{\mathrm{A}}$ & $107.5^{\mathrm{B}}$ \\
\hline Simulated intestinal release (\%) & $100^{\mathrm{A}}$ & \\
\hline
\end{tabular}

\footnotetext{
${ }^{A-B}$ Means \pm standard deviation with different superscript letters in the same row indicate significant differences $(P<0.05)$ among the studied samples.
}

Table 3: Effect of Outlet Temperature on Physicochemical Properties and Gastrointestinal Survival of Spray Dried WPI-Pullulan Microcapsules Loaded with L. acidophilus NRRL B-4495

\begin{tabular}{|c|c|c|c|c|c|}
\hline \multirow{2}{*}{ Physicochemical Characteristics } & \multicolumn{5}{|c|}{ Outlet Temperature (ㅇ) } \\
\cline { 2 - 6 } & Initial & $\mathbf{3 5}$ & $\mathbf{4 5}$ & $\mathbf{5 0}$ & $\mathbf{5 5}$ \\
\hline \hline Survival (\%) & - & $95.43^{\mathrm{a}}$ & $90.99^{\mathrm{b}}$ & $87.03^{\mathrm{b}}$ & $75.84^{\mathrm{c}}$ \\
\hline Recovery (\%) & - & $60^{\mathrm{a}}$ & $69^{\mathrm{b}}$ & $84^{\mathrm{c}}$ & $8,76^{\mathrm{c}}$ \\
\hline Microbial load (CFU/g) & 9,862472 & $9,14^{\mathrm{a}}$ & $8,82^{\mathrm{b}}$ & $7,59^{\mathrm{c}}$ \\
\hline Moisture Content (\%) & - & $13^{\mathrm{a}}$ & $9.80^{\mathrm{b}}$ & $4.09^{\mathrm{c}}$ & $3.12^{\mathrm{d}}$ \\
\hline Aw & & $0.68^{\mathrm{a}}$ & $0.53^{\mathrm{b}}$ & $0.43^{\mathrm{c}}$ & $0.34^{\mathrm{d}}$ \\
\hline Diameter $(\mu \mathrm{m})$ & - & $71.4^{\mathrm{a}}$ & $66.8^{\mathrm{b}}$ & $46.9^{\mathrm{c}}$ & $31.8^{\mathrm{d}}$ \\
\hline
\end{tabular}

\footnotetext{
${ }^{a d}$ Means \pm standard deviation with different superscript letters in the same row indicate significant differences $(P<0.05)$ among the studied samples.
} 
survival rate by increasing outlet temperature has been stated by various researchers $[7,11]$.

\section{REFERENCES}

[1] Carvalho AS, Silva J, Ho P, Teixeira P, Malcata FX, Gibbs P. Relevant factors for the preparation of freeze-dried lactic acid bacteria. Int Dairy J 2004; 14(10): 835-47. http://dx.doi.org/10.1016/j.idairyj.2004.02.001

[2] De Giulio B, Orlando P, Barba G, Coppola R, De Rosa M, Sada A, et al. Use of alginate and cryo-protective sugars to improve the viability of lactic acid bacteria after freezing and freeze-drying. World Journal of Microbiology and Biotechnology 2005; 21(5): 739-46. http://dx.doi.org/10.1007/s11274-004-4735-2

[3] Su LC, Lin CW, Chen MJ. Development of an Oriental-style dairy product coagulated by microcapsules containing probiotics and filtrates from fermented rice. Int $\mathrm{J}$ Dairy Technol 2007; 60(1): 49-54. http://dx.doi.org/10.1111/j.1471-0307.2007.00292.x

[4] Carvalho AS, Silva J, Ho P, Teixeira P, Malcata FX, Gibbs P. Effects of various sugars added to growth and drying media upon thermotolerance and survival throughout storage of freeze-dried Lactobacillus delbrueckii ssp. bulgaricus. Biotechnol Prog 2004; 20(1): 248-54. http://dx.doi.org/10.1021/bp034165y

[5] Chávez B, Ledeboer A. Drying of probiotics: optimization of formulation and process to enhance storage survival. Drying Technology 2007; 25(7-8): 1193-201. http://dx.doi.org/10.1080/07373930701438576
[6] Ying D, Sun J, Sanguansri L, Weerakkody R, Augustin MA. Enhanced survival of spray-dried microencapsulated Lactobacillus rhamnosus $G G$ in the presence of glucose. Journal of Food Engineering 2012; 109(3): 597-602. http://dx.doi.org/10.1016/j.jfoodeng.2011.10.017

[7] Behboudi-Jobbehdar S, Soukoulis C, Yonekura L, Fisk I. Optimization of Spray-Drying Process Conditions for the Production of Maximally Viable Microencapsulated L. acidophilus NCIMB 701748. Dry Technol 2013; 31(11): 1274 83. http://dx.doi.org/10.1080/07373937.2013.788509

[8] Dianawati D, Mishra V, Shah NP. Role of Calcium Alginate and Mannitol in Protecting Bifidobacterium. Appl Environ Microb 2012; 78(19): 6914-21.

http://dx.doi.org/10.1128/AEM.01724-12

[9] Rajam R, Karthik P, Parthasarathi S, Joseph GS, Anandharamakrishnan C. Effect of whey protein - alginate wall systems on survival of microencapsulated Lactobacillus plantarum in simulated gastrointestinal conditions. Journal of Functional Foods 2012; 4(4): 891-8. http://dx.doi.org/10.1016/j.jff.2012.06.006

[10] Koç M, Koç B, Yilmazer MS, Ertekin FK, Susyal G, Bağdatıoğlu N. Physicochemical Characterization of Whole Egg Powder Microencapsulated by Spray Drying. Drying Technology 2011; 29(7): 780-8. http://dx.doi.org/10.1080/07373937.2010.538820

[11] Gardiner GE, O'Sullivan E, Kelly J, Auty MAE, Fitzgerald GF, Collins $\mathrm{JK}$, et al. Comparative survival rates of humanderived probiotic Lactobacillus paracasei and L. salivarius strains during heat treatment and spray drying. Applied and Environmental Microbiology 2000; 66(6): 2605-12. http://dx.doi.org/10.1128/AEM.66.6.2605-2612.2000 